Article

\title{
Extractive Poetics: Marine Energies in Scottish Literature
}

\author{
Alexandra Campbell \\ School of Literatures, Languages and Cultures, University of Edinburgh, Edinburgh EH8 9LH, UK; \\ Alexandra.campbell@ed.ac.uk
}

Received: 26 September 2018; Accepted: 16 January 2019; Published: 18 January 2019

\begin{abstract}
Following the recent call to 'put the ocean's agitation and historicity back onto our mental map. and into the study of literature' (Yaeger 2010), this article addresses the histories and cultures of marine energy extraction in modern Scottish literature. The burgeoning discipline of the Energy Humanities has recently turned its attentions towards Scottish literature as a valuable area of study when contemplating the relationship between energy and cultural production. Most recently, scholars have focused their analysis on the histories of North Sea oil and gas production and have worked to juxtapose the long histories of land clearance in the Highlands and islands alongside contemporary narratives of exile and exploitation experienced by Scotland's coastal oil communities. The forms of spatial injustice incurred through the recent histories of what Derek Gladwin terms 'Oil Clearance' (Gladwin 2017) or Graeme Macdonald identifies as 'petro-marginalisation' (Macdonald 2015), is often solely registered through terrestrial environments. This article urges the adoption of an oceanic perspective, one which registers how the extractive politics of modern petroculture in Scotland not only presents major challenges for terrestrial environments and communities, but holds specific ramifications for the ways in which we currently imagine and interact with oceanic space. Indeed, as Macdonald has noted, the North Sea is in many ways 'wholly regarded as a productive environment of marine capitalism synonymous with oil' (2015). What does it mean to read the ocean through oil? By adopting an oceanic perspective, this article considers the ways in which the exploitative dynamics of offshore petroculture in the 1970s coincides with an incredibly damaging and problematic cultural construction of the ocean. But as Scotland moves towards a new era of low-carbon energy production, how might this construction of the ocean change? The closing half of this article considers the ways in which the extractivist histories and spatial injustices of petroculture are resisted through contemporary poetic engagements with new marine-based energy technologies, namely, wave and tidal power. In examining a range of work from artists and poets such as Alec Finlay, Laura Watts, Lila Matsumoto and Hannah Imlach, this article further argues that the recent turn towards marine renewables not only signals a new future for a low-carbon Scotland, but that the advent of renewable technologies provides contemporary poets with new materials through which to imagine alternative models of community, power, and relation in an era of environmental change.
\end{abstract}

Keywords: Blue Humanities; Ecopoetics; Marine Renewables; North Sea Oil; Orkney; Petroculture

\section{Introduction}

In positioning the seas and oceans as sites of cultural and literary production the recent rise of the 'Blue Humanities' (Mentz 2015, p. xxviii) or 'critical ocean studies' (DeLoughrey 2017, p. 32) poses questions of human culture and history within a distinctly watery frame. Following this recent call to 'put the ocean's agitation and historicity back onto our mental map. and into the study of literature' (Yaeger 2010, p. 538) this article turns its attention to the offshore energies, cultures, and ecologies of the North Sea. Recent Energy Humanities perspectives of Scottish literature and culture tend to focus their attentions on the terrestrial impacts of North Sea oil, juxtaposing the spatial injustices evident 
in the long histories of land clearance in the Highlands and islands alongside new forms of 'petro marginalization' (Macdonald 2015, p. 55) and 'Oil Clearance' (Gladwin 2017, p. 99) experienced by Scotland's coastal oil communities. Within this growing body of energy scholarship. the cultural and ecological impacts of North Sea oil are registered through texts whose central narratives emphasise the 'displacing forces of oil' (Gladwin 2017, p. 92). While such critical and creative work does well to interrogate the relationship. between offshore extraction and onshore eviction, the marine registrations of oil production remain unexplored. This article urges the adoption of an oceanic perspective of Scottish energy cultures, one that registers how the extractivist politics of oil production in Scotland not only presents major challenges for terrestrially-bound environments and communities, but holds specific ramifications for the ways in which we currently imagine and interact with oceanic space. As Graeme Macdonald asserts, since the oil boom of the 1970s, the North Sea can be 'wholly regarded as a productive environment of marine capitalism, synonymous with oil' (Macdonald 2015, p. 41). What does it mean to read the ocean through oil? How might the installation of specific offshore technologies alter our cultural and ecological relationship. with marine environments? How does Scottish literature respond to different waves of techno-capitalist development in the North Sea? In answering these questions, the opening half of this article considers the ways in which marine energy cultures, and particularly the dynamics of offshore oil production, coincide with an incredibly damaging and problematic cultural construction of the ocean.

The recent rise of critical ocean studies has in part emerged in response to the techno-capitalist transformation of the sea: 'contemporary interest in the oceans is due in part to their reframing from what was once figured as a mysterious, blank res nullius or no man's land to a final frontier for privatised extractivism' (Price 2017, p. 46). Arguably however, the exploitative practices and politics of offshore extractivism have not emerged in opposition to such sublime constructions of the ocean as aqua nullius, but have, in fact, fed off of cultural conceptions of the ocean as a mysterious, infinite, and resilient space that supposedly exists beyond the bounds of human knowledge. Indeed, as Stacy Alaimo argues, the discourse of oceanic resilience has enabled humans 'not only to deposit such things as hazardous waste in the seas, but also to dispose of culpability, responsibility, and concern' (Alaimo 2012a, p. 177). Seemingly impervious to anthropogenic harm, the vast and mysterious ocean emerges as 'a humanized technoscap. that places new demands on our eating and disposal habits and also on our relation to literature' (Yaeger 2010, p. 530). For Patricia Yaeger, the 'myth of ocean magnanimity' (Yaeger 2010, p. 530) not only encourages a construction of the ocean as a dumping ground for petromodernity, but further 'encourage[s] humans to treat it as an inexhaustible storehouse of goods'; an attitude that has in turn led to 'feckless oil drilling and over fishing' (Yaeger 2010, pp. 531, 535). However, such constructions of the seemingly inexhaustible and invulnerable ocean have begun to change in the light of recent movements towards the use of marine-based renewable energies such as in Scotland. Following the establishment of the European Marine Energy Centre (EMEC) off the coast of Orkney in 2003, the notion that the North Sea is 'synonymous with oil' (Macdonald 2015, p. 41) may no longer hold true. With over 45 projects currently being tested in Orkney's tempestuous waters, the EMEC is considered by many to be 'the industry beacon' for marine renewable technologies, making Scotland 'the global centre for the marine energy industry' (Watts and Winthereik 2018, italics in original, chp. 13, para. 26). In opposition to the displacing forces of the multinational petroleum industry, the site-specific installations of wave and tidal technologies produce a different mode of ecological relation with marine environments. While the EMEC is, of course, another instance of multinational energy investment and a hallmark of 'blue capital', the site-specific dimensions of wave and tidal energy imparts an interesting sense of locality to this mode of energy production. To put it simply, the tide cannot be moved. Indeed, despite its reliance upon the flux and fluidity of the ocean, marine renewable energy is in many ways more grounded than oil and gas products that can be piped, stored, shipped, and ultimately burnt wherever they are needed.

Current academic interests in the renewable energy industry in Scotland are often geared towards deciphering the social, economic, and environmental changes that accompany the installation of 
renewable technologies, with few studies contemplating cultural registrations of such technologies. The second half of this article analyses the ways in which the extractive histories and politics of oceanic petroculture are resisted through contemporary poetic engagements with other marine-based energy technologies, namely wave and tidal power. The article examines a range of works that have recently emerged in response to Scotland's renewable energy seascapes, including the collaborative poetry project by Alec Finlay and Laura Watts Ebban an Flowan (Finlay et al. 2015); the collaborative poetry and soundscap. project 'Minnmouth' (Finlay et al. 2016) by Alec Finlay, Hanna Tuulikki and Lucy Duncombe; and the poetry/sculpture project by Lila Matsumoto and Hannah Imlach 'Blàthan Briste IBroken Flowers' (Taigh Chearsabhagh Museum and Arts Centre 2017). The article argues that the recent turn towards marine renewables not only signals a new future for a low-carbon Scotland, but that the advent of renewable technologies provides contemporary poets with new materials through which to imagine alternative models of community, power, and relation in an era of environmental change. While their specific artistic interactions with renewable technologies differ in key ways, at their core each of these projects pursues a mode of writing that is responsive to, and responsible towards, the specific marine environments in which they are produced. This article is thus particularly interested in the ways in which different extractive technologies align with specific cultural constructions of marine space. As Helen Rozwadowski suggests '[b]oth the ocean's scale and its opacity mean that knowledge of the sea is mediated by technology and knowledge systems. These include the gear and knowledge of fishermen, navigators and others who work at sea as well as the tools and understanding of modern science' (Rozwadowski 2010, p. 21). It therefore follows that specific technologies and knowledge systems have the ability to shap. particular modes of seeing, reading, and understanding the ocean. Indeed, for Janine MacLeod the 'material relationship. between petrochemicals and water [ ... ] have significant implications for everyday affective experience. As rivers, aquifiers, and oceans accumulate the long-lived by-products of fossil fuel dependence and capitalist social relations, the meanings and emotional resonances of water are likewise profoundly altered' (MacLeod 2017, p. 264). The second half of this article thus suggests that where the exploitative discourses of offshore oil production serve to reinforce harmful narratives of oceanic inexhaustibility, sublimity and resilience, contemporary poetic responses to renewable energy technologies cultivate an alternative affective oceanic discourse, one that accentuates notions of sustainability, materiality, and resistance. The article concludes by considering the extent to which poetry itself might be regarded as a 'knowledge system' or 'technology' that is able to navigate new modes of ecological relation with the sea.

To embark upon any discussion regarding marine energy cultures and Scottish literature it is first necessary to outline a brief history of the North Sea oil and gas industry, and the ways in which the birth of offshore oil in the UK coincides with a particular oceanic imaginary that is tied to specific marine legislature and oceanic technologies. Following the discovery of huge onshore gas fields in the Netherlands in 1959, the first seismic reflection survey was carried out on the North Sea seabed in 1962 with the hopes of uncovering similar energy reserves buried deep beneath the ocean floor. The survey concluded that there were indeed potential fuel reserves lying dormant under the seabed, however, drilling was not yet possible as the bordering states of the North Sea had yet to agree the ownership of the continental shelf beyond the limits of their defined territorial waters. The question of the extent to which states were able to claim territorial control over the seabed and its resources had been raised roughly two decades earlier with the 1945 Truman Proclamation, when the USA declared sovereign rights over its continental shelf to the limit of 200 nautical miles and to a depth of 200 metres. As Elizabeth DeLoughrey has persuasively argued elsewhere, the establishment of the Truman Proclamation signaled an 'unprecedented era of global ocean governance and militarization' (DeLoughrey 2010, p. 705). The proclamation 'catalyzed the most radical remapping of the globe in modern history, expanding all coastal nations through an Economic Exclusion Zone [EEZ] of two hundred nautical miles' amounting to the state privatization and control of approximately 'thirty-eight million square nautical miles of the global sea [or] 35\% of the world's ocean' (DeLoughrey 2010, p. 705). Importantly, the Truman proclamation does not merely extend over a horizontal plane that is limited 
to the ocean's surface, but also extends to 'submarine and air space claims that protect the passage of nuclear submarines, sea-launched missiles, and maritime surveillance systems' (DeLoughrey 2010, p. 706). This claim for territorial depth in addition to territorial breadth was in many ways 'precipitated by the increased importance of oil resources, underscored by the necessities of World War II and by the development of exploration and exploitation technology' (Treves 2015, p. 10). Indeed, the legal regime of the continental shelf (which differs to the physical limits of the geographical continental shelf) was 'directly tied to the potential for oil and gas in the seafloor area' (McDorman 2015, p. 183).

The later 1958 Geneva Convention on the Law of the Sea sought to consolidate and establish the key legal attributes of the continental shelf regime first laid out by the Truman Proclamation. The principal features of the convention reflected 'the economic and geopolitical importance for coastal States of controlling offshore hydrocarbon exploration and exploitation in their adjacent seafloor areas' (McDorman 2015, p. 186). By 1960, 18 nations had reported to 'possess offshore commercial production of gas and oil, while 60 engaged in exploration and development' (Freeman 1970, p. 115). While the Space Race was occupying the skies above, the seas below were also witnessing a scramble for power and control on an unprecedented level as exploration and exploitation moved 'farther seaward as new devices and techniques be[came] available' (Freeman 1970, p. 115). With the development of new deep-sea drilling technologies, coastal states were (and still are) able to extend their national sovereignty into resource-rich waters and to gain exclusive control over fish, gas, and oil reserves. Indeed, 'at no other time in history are so many transnational oil companies prospecting and drilling for petroleum and hydrocarbons on the seafloor' (DeLoughrey 2007, p. 32). Hydrocarbon extraction was also at the centre of the later 1964 UK Continental Shelf Act (1964), which ratified the earlier 1958 Geneva Convention in establishing a state's 'sovereign rights over its continental shelf for the purpose of exploring it and exploiting its natural resources' (Dean 1958, p. 619). The 1964 act signaled a new era of offshore development and oceanic exploitation for the UK, where the legislative emphasis on territory, sovereignty, and exploitation further incurred a dramatic political and cultural reconfiguration of oceanic space. Across the next four years some dozen gas fields were discovered across the North Sea and were immediately brought under the exclusive jurisdiction of their adjacent coastal state. The first major commercial oil discoveries occurred in 1969 when Phillip. Petroleum first unearthed the giant Ekofisk Oil Field in the Norwegian sector of the North Sea. This was followed a month later by the discovery of the UK's first major oil field by the drilling rig Sea Quest, which unearthed the Montrose and Arbroath Oil Fields about 130 miles east of Aberdeen.

\section{2. 'There's a Boom-Time a-Coming': Scottish Literature and North Sea Oil}

Where recent petrocultural engagements with Scottish literature (Gladwin 2017; Logar 2011; Macdonald 2015, 2017) serve to highlight the terrestrial registrations and spatial injustices of oil production, the compartmentalization of the ocean in relation to offshore oil extraction necessitates further analysis. Despite the prominence of North Sea oil in UK legislation, media, and politics, the actual number of overt petronarratives to emerge from the 'oil boom' are surprisingly sparse. Since the 1970s, two works in particular have served to attract scholars interested in the ways in which Scottish texts register the modes of cultural and ecological displacement enacted by oil: John McGrath's 1973 avant-garde theatre production The Cheviot, the Stag and the Black, Black Oil, and George Mackay Brown's 1972 novel Greenvoe. The island communities of Orkney and Shetland were perhap. the most radically altered by the arrival of oil in the 1970 s. $^{1}$ Greenvoe is both prophetic and apocalyptic in its

1 For Maggie Fergusson, Greenvoe's central narrative directly aligns with the arrival of oil in Orkney in the early 1970s when 'Kirkwall was to become an international port for heavy tankers; a disused Second World War airfield at Skeabrae was to be redeveloped as an airbase for jumbo jets from Texas; part of the parish of Orphir-an area of extraordinary pastoral beauty - was to be taken over for the construction of oil platforms; the Bay of Houton, on the south coast of mainland Orkney, was to be dammed as a dry dock, and Midland Hill to be mined to provide the necessary stone' (Fergusson 2006, p. 222). 
depiction of the decimation of the fictional Orkney island community of Hellya, which is overtaken by the installation of a new project referred to ominously as 'Black Star'. The novel brings to light growing anxieties regarding Orkney's fate in relation to new extractivist discourses emanating from the island's relation to both offshore oil extraction and onshore uranium mining. While the sense of looming disaster is present from the opening of the novel, the collapse of the island community and its environment is felt most distinctly in the opening lines of Chapter 6:

The cone of Korsfea was shorn off. The loch of Warston was drained; red-throated divers and eiders and swans had to seek other waters. Hellya was probed and tunneled to the roots. [ ... ] men with enormous baggage landed on the pier from the Skua. [ ... ] All that week the Skua ferried more and more workers across; within a week they outnumbered the island people. (Mackay Brown 1972, p. 241)

While the narrative centers on the catastrophic impact of operation Black Star on the local community, noting the influx of foreign laborers who begin to displace the local crofting community, the novel also registers the modes of displacement felt by the island's nonhuman populations. As the Skua ferry (named after a large species of seabird) shuttles its passengers back and forth at ever-inflating prices, the island's wild bird populations are displaced through the creation of new large-scale loading bays, helipads, tanker transport routes and ferry ports. In this accelerated petroscape, the slow wheel of native birdcalls gives way to new mechanised 'noises-a roar and a clangour from morning to night' where the constant flurry of 'lorries, more hut sections, cranes, bulldozers and transformers', decimates the habitats of seabirds who are forced to make 'wider and wider circuits about the cliffs' (Mackay Brown 1972, p. 242).

Across the novel, the aural and physical eviction of the nonhuman community serves to accentuate the disruption of the natural rhythms of Hellya brought about by the poisonous pulse and 'radiance of Black Star' (Mackay Brown 1972, p. 244). As the 'black star explode[s] slowly under the hills' (Mackay Brown 1972, p. 243), both the land and sea surrounding are degraded:

There was pollution in the sea. Bert Kerston hauled his creels in the rocky sheltered bay beyond the Taing, and four of the seven lobsters were inert. [ ... ] He noted that on this particular day the burn, as far as he could see, was all khaki coloured scum, and the filth fumed out over the water of the bay for half a mile and more. A haddock floated on the surface, belly up. (Mackay Brown 1972, p. 259)

Besides, worst of all, the sea was rotten, dead haddocks drifting through the Sound. This had never been known before. There would soon be no work for him or any other fisherman out of Hellya or Quoylay. (Mackay Brown 1972, p. 260)

No longer solely attached to the work of farming and fishing, drilling and harvesting are coopted by a new international energy regime that disrupts and dismantles the agricultural and fishing industries of the islands. As the island's farms and old family homes are bought or bulldozed, the land is divested of its cultural history and its natural rhythms are irrevocably altered. While Greenvoe's narrative tends to describe the installation of operation Black Star through terrestrial terms, aligning the project with acts of tunneling, mining, and 'the whine of pneumatic drills and a single volley of blasting' (Mackay Brown 1972, p. 259), the continued references to the island's depleted fish stocks and polluted waters reveal how the Black Star's appropriation of the rural landscap. is accompanied by the total corruption of marine environments.

As Macdonald notes, Greenvoe follows a narrative structure that is common amongst other 'oil-encounter' novels in its tracing of the 'typically aggressive destruction and transformation' (Macdonald 2017, p. 293) of the local environment in which 'social space cedes to resource space; foreign labourers outnumber locals; commodities multiply and prices inflate; and local laws and customs are questioned and traduced' (Macdonald 2017, pp. 293-95). The novel's examination of the different forms of contemporary land clearance, the resultant displacement of local communities, 
and attendant degradation of marine environments reveals the wider functioning of extractivist industries that operate through 'iniquitous patterns of land seizure and capital accumulation by dispossession, accompanied by the threat of environmental catastrophe' (Macdonald 2015, p. 230). In McGrath's experimental theatre production, The Cheviot, we see these same narrative patterns of exploitation, eviction, and environmental collapse emerge as the play traces the long and violent resource histories of Scotland. Much as Greenvoe's 'narrative arrangements register [the] uneven and accelerated development' associated with 'oil's short-termist character' (Macdonald 2017, p. 298), in The Cheviot we see a similar oil aesthetic emerge through the speed and dynamism of McGrath's 'theatre of displacement that intends to register the distress and uprooting consonant with capitalist modernity' (Macdonald 2015, p. 21). While the petrospacial dynamics of McGrath's play have been read in terrestrial terms, an oceanic reading demonstrates the play's hitherto underexplored perspective on marine exploitation and the damaging cultural transformation of the sea that accompanies seemingly inexhaustible 'boom time' of oil.

In the play's final act, McGrath's interrogation of the exploitative politics and aesthetics of offshore oil production not only serves to critique a new era of oil clearances on land, but further reveals a growing concern with the enclosure of the sea by both the British state and multinational petroleum industries:

M.C.1 Shell-Esso of America, Transworld of America, Sedco of America, Occidental of America—and Lord Thomson.

M.C.2 Conoco, Amoco, Mobil, Signal.

Texas Jim All of America.

M.C.1 And British Petroleum [ ... ]

M.C.1 By 1963 the North Sea was divided into blocks.

M.C.2 By 1964 100,000 square miles of sea-bed had been handed out for exploration

(McGrath 2015, p. 150)

Here the Master of Ceremonies directly refers to the aforementioned 1964 Continental Shelf Act, in which the United Kingdom not only actively pursued the compartmentalization of the ocean, but did so with the express purpose of then selling off 'blocks' for petroleum prospecting by multinational corporations such as Shell, BP and Superior Oil (now a part of Exxon Mobil). ${ }^{2}$ Notably, McGrath describes the formal structure of the play as being similarly divided into 'blocks' (McGrath 2015, p. xv). As the MCs continue to note, in opposition to other oil-rich countries such as Norway, Algeria and Libya, the UK's handling of the North Sea fails to bring substantial oil reserves into public ownership. instead laying the seabed open to the unfettered and unregulated enterprise of the neoliberal market. As with the earlier forms of land enclosure dealt with in the play, in which local landscapes are carved out and redistributed by wealthy landowners who typically govern from elsewhere, in the oil 'block' we see how the boundaries of the North Sea are similarly redrawn along supposedly national lines before being dispersed amongst multinational corporations who refine the oil abroad before selling it 'back to us at three or four times the price' (McGrath 2015, p. 150). Despite the original Law of the Sea emphasizing forms of territorial control and state sovereignty over oceanic space we see in The Cheviot how the multinational petrostate supersedes any form of local or national control over marine (or land based) resources. The play's tracing of petroleum's endlessly mobile routes of production further accentuates the ways in which oil's extractivist mechanisms transform 'ostensibly productive common territory [ ... ] into private and speculative capital' (Macdonald 2015, p. 57). Importantly, the play's repeated gesturing towards offshore networks of financial and environmental exploitation prompts the need to recognize the ways in which 'clearance' is not a solely terrestrial

2 For a discussion of the initial consultation of oil corporations and subsequent legislation surrounding the legal and physical demarcation of offshore 'blocks' see: Alex Kemp 2012, 'Chapter 1: Initial Legislation and Licensing', in The Official History of North Sea Oil: Volume 1, The Growing Dominance of the State. London: Routledge, pp. 1-62. 
process, but is in fact a form of appropriation and displacement that can extend into that other 'common territory' of the ocean.

The failure of oil's supposedly emancipatory narrative is further exposed through the cartoonish character of Texas Jim, whose increasingly insidious songs serve to highlight the true cost of living within the neoliberal rhythms of 'a free country' (McGrath 2015, p. 149). His songs reveal a growing sense of disempowerment that accompanies the continued capitalist compartmentalisation of Scottish land and sea:

Texas Jim: Take your oil-rigs by the score, Drill a little well just a little off-shore

Pip. that oil in from the sea,

Pip. those profits-home to me. [ ... ]

So leave your fishing, and leave your soil.

Come work for me, I want your oil.

Screw your landscape, screw your bays

$I^{\prime} l l$ screw you in a hundred ways- $-[. .$.

All you folks are off your head

I'm getting rich from your sea bed

I'll go home when I see fit

And all I'll leave is a heap of shit.

(McGrath 2015, pp. 146-47)

As in Greenvoe, we see here how the industries, languages, and practices of the Highlands and islands are transposed onto the machinations of the petroleum industry. In these scenes, the cultural modes of song and dance become attached to the exuberant and accelerated impulses of oil, where Jim's increasingly haphazard choreography and up-temp. rockabilly rhythms transform the slow Highland ballads from earlier scenes into something more rapid and restless. The 'souped up' (McGrath 2015, p. 151) duet between the characters of Whitehall and Texas Jim emphasizes the extent to which the prospecting discourse of the petrocapitalist system has penetrated into the Scottish environment, whereby the piping of traditional song now heralds a future of new 'prospects' through the installation of pipelines and the 'building of oil rigs and houses and piers' (McGrath 2015, p. 152). The transformation of song, one of the key modes through which the marginalized communities present within The Cheviot are able to assert their identity and relationship with the land, further highlights the 'dispossessive impact of the "oil complex" on local communities in resource-rich landscapes' (Boyer and Szeman 2017, p. 153). While the speed and restlessness of these scenes registers the spatial politics of dispossession and displacement at work onshore, the 'exhausting' (McGrath 2015, p. xv) dances performed on stage serve to draw attention back to the supposedly inexhaustible offshore environments from which this energy originates.

As these scenes indicate, the 'boom time' (McGrath 2015, p. 151) experienced during the 1970s prompts a dramatic reconfiguration of the ocean as space once defined through community histories to one demarcated through speculative capitalist futures. Returning to the earlier suggestion that since the 1970s the North Sea can be regarded as a space largely synonymous with oil, it is interesting to note that Macdonald's demarcation of the North Sea as a 'productive' petrospace, is positioned in antithesis to the Highland landscap. which is 'repeatedly branded as a romantic space of open or untouched emptiness' (Macdonald 2015, p. 41). What is intriguing here is the way in which Macdonald indicates that the petrocultural industry has the power to not only physically alter both land and seascapes, but further has the ability to alter cultural and imaginative relationship. with oceanic space; transforming it from a once romantic and sublime space into a disenchanted site of industrial production. We see this transformation of oceanic space in The Cheviot during Texas Jim and Whitehall's duet. Their bizarre rock ballad that unfolds with 'suddenness, speed and accelerated action' (Macdonald 2015, p. 23), not only exposes the collusion between the British government (Whitehall) and multinational oil corporations (Texas Jim), but further serves to emphasize the total 'transformation of the environment' 
(Macdonald 2015, p. 23) that accompanies resource extraction regimes. In the 1974 BBC production, Whitehall and Texas Jim's duet is overlaid with images of giant rigs and tankers being launched into the North Sea. The visual spectacle of these massive structures crashing forcibly into the sea accentuates an overall sense of powerlessness as both the local community and the audience are unable to stop the continued flow of extractive technologies into the ocean. The scene reveals how within this era of offshore exploration and exploitation, the supposedly unfathomable ocean becomes newly legible through the technocapiatlist inscription of marine space in which our relationship with the ocean is newly mediated through the installation of rigs, oil terminals, submarine pipelines, and transoceanic shipping lanes. The transformation of the once sublime seas is emphasized in the dialogue between the Crofter and the Wife who in their own way seek to capitalize on the new petroscap. that surrounds them:

Wife You'll have to come see the oil-rigs—oh, they're a grand sight, right enough. [ ... ]

Crofter And you'll see the bonnie big tankers come steaming up the loch without moving from your chair. [...]

Wife When the weather clears up. you'll be wanting down to the shore to see the pollution-it's a grand sight, right enough.

\section{(McGrath 2015, p. 156)}

The Wife and Crofter's conversation serves to satirize the supposedly endless potential brought forth from drilling for 'Oil, oil, underneath the sea' (McGrath 2015, p. 156), revealing how the allegedly empowering 'free play of the market' (McGrath 2015, p. 158) will never benefit those most in need. At the close of the play, the emergence of the polluted petro-ocean exposes how the wide-scale installation of offshore oil technologies during the 1970s transforms the once romantic vistas of seas and lochs into 'just another site where human relations take shap. and connect through lowcost hardware and the freedom of an unregulated environment' (Yaeger 2010, p. 532). While such romantic discourses are in themselves problematic, the play's focus on the degradation of marine environments serves to undermine petrocultural narratives of resilience and inexhaustibility.

As the oceanographer Sylvia Earle laments, the common cultural construction of the ocean as a space 'so vast, so resilient, it shouldn't matter how much we take out of-or put into-it' (Earle 2009, p. 12), has cultivated a global crisis of oceanic exploitation and exhaustion. Indeed the petroleum industry at large feeds off of the cultural construction of the ocean as a vast, infinite, and resilient storehouse in which 'There's many a barrel of oil in the sea I All waiting for drilling and piping to me' (McGrath 2015, p. 151). The supposedly endless flow of oil capital is captured through Jim's nursery-rhyme style song in which he ecstatically counts off his accumulating funds: '8 91011 12 | Billion of dollars all to myself', '21 2223 24 I Billion Billion dollars more' (McGrath 2015, p. 148). As the pace of Jim's song quickens in line with the oil that 'begins to flow' (McGrath 2015, p. 148), the play highlights the ways in which Jim's newfound financial liquidity is accompanied by more disturbing forms of fluidity in the shap. of an oil spill. As Jim 'Tiptoe[s] through the oily sand' (McGrath 2015, p. 148), the play registers the ways in which overflowing petroleum revenues often coincide with the literal overflow of oil spills. Declaring: 'I don't give a damn for your fancy shore', 'I'll go home when I see fit/all I'll leave is a heap of shit' (McGrath 2015, p. 148), Jim's song reveals the ways in which the oil industry at large rests on the rhetoric of the sublime and infinite seas, wherein the depiction of the ocean as both a rich and bountiful, yet paradoxically empty space is central to the circuitous petronarrative of drill, spill, and drill again. Within such narratives the supposed vastness of the ocean renders the scale of any spill seemingly insignificant. During the period from '1979 to 1984 inclusive, the total stabilized crude oil production was $574.3 \mathrm{Mt}$ [megatons]. There were 335 spills, resulting in $1.782 \mathrm{kt}$ [kilotons] of spilled oil' seeping into the North Sea (Larminie et al. 1987, p. 489). Describing such spills as 'isolated', 'relatively minor', and 'not significant' (Larminie et al. 1987, p. 489) the work of Larminie et al. highlights the ways in which petroleum production relies upon, and perpetuates, perceptions of the ocean as a vast and resilient site. Through its attention to the environmental impacts of offshore oil production, The Cheviot promotes the need to contravene such constructions of the ocean. 
The later scenes between the Crofter and the Wife, in which they lament the lack of fish in Scottish waters, directly recalls earlier songs in which the character Loch (played by the same actor as Texas Jim) proclaims 'There's a many a fine shoal of fish in the sea I All waiting for catching and frying for tea' (McGrath 2015, p. 92). In the play's final block, the ocean is revealed to be distinctly finite and fragile. While Jim's blasé attitude towards the corruption of the coastal environment serves to accentuate the harmful discourse of disposal that accompanies offshore oil production, as the play move towards the concluding scenes the narrative becomes increasingly alert to the environmental and economic realities of oceanic exhaustion. The final moments of Texas Jim and Whitehall's duet serves to emphasize the limits of the supposedly endless ocean, where the closing image of Jim pouring out celebratory 'drinks of oil' (McGrath 2015, italics in original p. 152) is undercut by the fact that at the end of the scene there is 'No oil in can' (McGrath 2015, italics in original p. 152). As fish stocks dwindle, and coastlines deteriorate, The Cheviot actively dispels the 'myth of oceanic magnanimity' (Yaeger 2010, p. 530) revealing that the seemingly infinite ocean with its endless flows of oil, will eventually run dry. In so doing, The Cheviot not only exposes the terrestrial forms of spatial injustice that emerge as a result of exploitative resource regimes, but further reveals the economic and environmental consequences of annexing the ocean.

While tracing the cultural contours of the petro-ocean in Scottish literature remains an important area for analysis, as Rachel Price rightly notes, contemporary oceanic criticism needs to move 'beyond simply lamenting deep sea trawling or narrating how the oceans were once free and now are militarized and carved up to facilitate global expansion, since doing so unintentionally reinforces stories about the ineluctability of capitalism's reign' (Price 2017, p. 49). Thus far this article has registered the justifiable lamentations of Scottish petroliterature on the degradation of the North Sea, however, the second half of this article considers the extent to which contemporary poetry emerging from Scotland's current era of renewable energy production allows authors to resist and reimagine petrocapitalist relationship. with oceanic space. Importantly, through their work the poets and artists examined in the following section do not only engage the ocean as a site 'wholly synonymous with global capitalism' (Price 2017, p. 49), but further look to the ocean as both a medium and a methodology of creative resistance.

\section{Resisting the Petro-Ocean: Renewable Energy and Contemporary Poetry}

Where the texts of the 1970s centre on feelings of dislocation, dispossession, and displacement, the recent swell of renewable energy-focused creative projects emerging from across Scotland's island communities works to establish alternative oceanic narratives that resist and reimagine the discourses of powerlessness and pollution that emanate from the petro-ocean. In comparison with the extractive discourses of the earlier petronarratives of the 1970s, I want to suggest that the recent transition towards renewable energy in Scotland not only holds the potential to influence alternative models of community on land, but also holds significance for new cultural understandings of the ocean at large. The past decade has begun to herald a new era of low-carbon energy production in Scotland, with numerous politicians and companies comparing the transition towards offshore wind, wave, and tide as akin to the oil boom of the 1970s. In 2010 the Offshore Valuation Group report declared that: 'We find ourselves [with offshore renewable energy] in a comparable position to that of the nascent UK oil and gas companies in the 1970s' (The Offshore Valuation Group 2010, p. 8) and suggested that with a steady deployment of a mix of renewable energy technologies, including fixed wind, floating wind, wave, tidal stream and tidal range, by 2050 the production of electricity by renewables would be 'equivalent to 1 billion barrels of oil' roughly the same 'level of production experienced by the UK's North Sea oil and gas over the four decades leading up to 2008' (The Offshore Valuation Group 2010 , p. 20). The constant framing of renewable energy production through oil is perhap. surprising at first, but it is important to note that these comparisons usually occur at a purely financial, as opposed to environmental or social, level. As the work of the poet and ethnographer Laura Watts makes clear, the move towards renewable energy technologies in Scotland not only holds the potential for significant economic transformation, but further signals an opportunity to conceive of alternative 
'social, technical and environmental relations and exchanges' (Watts 2014, p. 32), to which I would add cultural and ecological relations and exchanges.

In Orkney, understanding energy infrastructure as a 'material system' means registering energy as a distinctly oceanic product. As Watts and Winthereik note, 'in high-energy edge locations, modern infrastructures, such as electricity, are visible networks and well known to those who live with and without them' (Watts and Winthereik 2018, chp. 13, para. 57). In Orkney, the extreme tides and storms that fuel the marine energy industry also frequently disrup. community access to fresh food and fuel: 'In Orkney the so-called lifeline ferry can stop for several days during winter storms, meaning that fresh food runs out at the supermarket. The electricity cables strung up on poles over the islands can be downed due to fierce winds, and the lights and phones can go out' (Watts and Winthereik 2018, chp. 13, para. 55). Thus, the reliance of Orkney's electrical infrastructure and transportation systems on the surrounding marine environment not only places the sea at the forefront of social and cultural relationships, but further renders Orkney's energy infrastructure distinctly 'visible and embodied' (Watts 2014, p. 30). In her poem 'Liminal Futures', Watts explores this sense of material agency as felt at the edge of the sea:

'You are connected to the weather here,

connected to the supply chain', says a local librarian.

'There is a sense of the interconnectedness of things'.

'Western consumerism is tempered,' she says.

There is clear green water always in sight,

between you and your wants;

a ferry or two,

between want and can have. [ ... ]

The infrastructure of Western world living

is laid bare and skin-close:

an insistent-touch of telecoms and transport;

the smell of energy on the wind.

(Watts 2014, p. 21)

Across the poem, Watts exposes the ways in which wind and wave dictate not only the island's energy infrastructure and future, but every facet of domestic island life. Key transport routes are disrupted by the 'most treacherous waters, ridden with whirlpools' that prohibit the delivery of both 'food and fuel' leaving 'empty shelves' across the island (Watts 2014, p. 21). The manifold use of the term 'ridden' is important here, where the term simultaneously points towards the sheer amount of potential of energy that can be harnessed in these waters, while also conjuring a sense of danger. Rather than positioning the sea as a conduit to capital and 'Western consumerism', the poem highlights the ocean's physical 'resistance to transport' (Watts 2014, p. 21), where to be 'interconnected' with high-energy water is to live in a state of constant risk. The poem's attentiveness to the materiality of the sea contrasts with the earlier songs of Texas Jim whose description of transnational offshore petroleum production highlights the abstract fluidity and mobility of the petrocapitalist world system and the ways in which it renders the ocean into 'a space of transit in which the sea is barely present' (DeLoughrey 2010, p. 704). In opposition to the affective register of oil narratives such as Greenvoe and The Cheviot in which the motifs of 'exuberance' and 'catastrophe' (Buell 2012, p. 291) serve to dislocate extraction culture from its immediate environment, Watts's poem renders renewable energy narratives as something distinctly local and tangible, revealing it to be a direct 'effect of its particular location, its particular geography and history, its particular relations and obligations between people, places and things' (Watts 2014, p. 33). Thus, where petrocultural narratives often engender a sense of displacement and dislocation between people, energy and landscape, Watts's poems highlight a sense of intimate, if precarious, interconnection between the island community, renewable technologies, and marine environments. 
In their collaborative collection, Ebban an' Flowan, Laura Watts and Alec Finlay further examine the relationship. between community and marine environments through a series of poems that seek to embed renewable energy technologies into local mythology and language. The collection proposes that just as other coastal industries, such as fishing, possess their own particular language, so too can oceanic technologies. The collection works to combat the dissociative tendencies of offshore energy production by rooting renewable energy in a sense of local place. As noted earlier, despite their reliance upon the flux and motion of oceanic environments, marine renewables are arguably more 'grounded' than offshore petroleum production. Much as 'tidal energy is I moored to the moon' (Finlay et al. 2015, p. 8), so too is each piece of machinery anchored to the ocean floor, with the ensuing energy produced routed back to the mainland via a single (often over-loaded) 'National Grid cable, an electrical lifeline I under the sea' (Watts 2014, p. 22). As the energy is landscap. specific, so too are the poems of the collection. Throughout the collection, Finlay's inclusion of concrete poems serves to highlight the unexpected groundedness of marine renewables. As the collection unfolds, the mimetic forms of the poems work to trace the tempestuous coastline of Billia Croo (home to the EMEC test site) and frequently mold themselves in the shap. of specific machines such as in the poem 'Streams' (Figure 1):

Tethered to the languages and histories of the North Sea, the poem not only map. the circular form of the OpenHydro test rig, but works to explore the ways in which energy, language, history, and ocean interact within Orkney's waters. As the foreword to the collection suggests 'Languages also have their tides-Orcadian Norn, as well as Shetlandic, the Norse tongues, Gothic, Scots and old English, reach all the way back to ancient Indo-European - their speech energetics and acoustic potential ebb and flow' (Finlay et al. 2015, p. 2). In the poem above, we get a sense of this active 'speech energetics' as the interlinking of 'AS', 'SEAS', 'STREAM', 'TO', '\&', 'FRO' serves to connect the different words for 'stream' that filter into the poem from across a range of North Atlantic languages; tethering the new technology to old histories of Nordic settlement and ongoing archipelagic connections across the North Sea. Just as Macdonald and Gladwin note how the theatrical energies of The Cheviot align with the accelerative mechanics of oil through the incorporation of fast-temp. songs and boisterous dancing, we see in 'Streams' a similar textual energy emerge whereby the poem's configuration not only echoes the dynamism of the OpenHydro turbines but is arranged in a way that encourages the continued looping reading of the text. With no discernable beginning or end, the poem itself is renewable; inviting different circulatory configurations upon every new encounter.

The attachment of language to technology invests both poetry and energy with local rhythms and intimate modes of knowing place. In contrast to the spectacular and accelerated scenes of oceanic catastrophe enacted by extraction technologies in The Cheviot and Greenvoe, the introduction of new energy technologies into the North Sea in Ebban an' Flowan is carefully intertwined with local customs, laws, and ways of knowing the ocean. One such example is the discussion surrounding 'Udal Law' in the collection's opening pages:

Udal Norse Law defining the extent of land and sea ownership. extending 'To the lowest point of the ebb, and also the ground further out, or marebakke, which is where the longshore becomes steep ... at the ebb of the tide' (Eileen Linklater 2002), variations define it extending, variously 'as far as a stone can be thrown, or a horse can be waded, or a salmon net can be thrown' (Charles Tait, n.d.).

Recent objections to leasing areas of the sea to consortia of multinational electricity companies and marine energy developers have been based on Udal law, some campaigners in Orkney and Shetland assert Udal Law as far as the continental shelf. (Finlay et al. 2015, italics in original p. 6)

The invocation of Udal rights to the seabed in Orkney has arisen at various points across the past few decades, most often as a means of contesting Crown Estate ownership and control over marine resources (to varying levels of success). As opposed to the extreme lengths and depths of ocean 
territorialisation as delineated by the Continental Shelf Act, Udal Law retains a sense of intimacy, community, and history where local residents not only turn to Udal Law as a means of asserting control over their immediate land and seascapes, but perceive it to be 'part of Orkney and Shetland identity and hence a continuing part of modern life' (Jones 2012, p. 115). Across Ebban an' Flowan, the poems reveal how in order for renewable energy projects to be successful they must not only be tethered to the physical seabed, a major feat in itself, but that in order 'to survive the wild tide I the device must be I lived and lored' (Finlay et al. 2015, p. 9). In order to be sustainably 'lived and lored' these technologies must become 'situated socioculturally and environmentally' (Watts 2014, p. 32) and are subsequently brought into contact with Orkney's high-energy waters through lengthy consultations with the Orkney community. As Watts notes, every new proposed project is approached with 'great care and personal investment, [that is] translated and negotiated through intense discussion and community debate' to the extent that energy becomes 'embedded in, and integral to, familial relations' across the archipelago (Watts 2014, p. 31). Speaking in her keynote paper 'Beside the Ocean of Energy Future Time' at Petrocultures 2018: Transitions at the University of Glasgow, Watts emphasized the need to include coastal communities and local forms of knowledge within the energy extraction process. Noting that local communities possess a unique form of 'ocean knowledge' (Watts 2018) in relation to the unmapped high-energy waters of the archipelago, Watts underlines the ways in which the success of marine renewables not only relies on the distinct physical features of the Orkney seascape, but is further reliant upon the 'situated knowledges' (Haraway 1988, italics in original, p. 581) of the community, where local residents are able to solve 'the problems of the engineer I through the eyes of the sailor' (Finlay et al. 2015, p. 10). Much as Rozwadowski argues that an understanding of the ocean is not only derived from the technologies of 'modern science' (Rozwadowski 2010, p. 521) but importantly includes the knowledge systems of all those who work at sea, so too do Finlay and Watts suggest that new 'tide and wave engineers' must 'turn to the lore of mariners, fisherfolk, and even mythic selkies or tangies, for new names and expressions' (Finlay et al. 2015, p. 2) that will allow for successful and sustainable marine energy production. Thus, where the arrival of oil in Greenvoe and The Cheviot corresponds with the utter destruction and dissolution of local knowledges and cultural practices, Finlay and Watts advocate the need for this new era of energy production to pursue a different path, one where the intimate and situated knowledges of local communities become integral to the continued progress of the renewable energy industry, as 'knowledge and vernacular sayings I transfer from the old fisherman I to the new breed of wave-wright' (Finlay et al. 2015, p. 15).

The transference of knowledge from local knowledge systems into different technologies is further explored in Finlay's second renewable energy poetry project titled 'Minnmouth' ${ }^{3}$ In this collection Finlay continues to contextualize renewable technologies within a longer oral history of Britain's east coast. By rooting his work in the environmental and linguistic histories of the coast, Finlay works to present poetry itself as a technology that is able to harness the creative energies of marine environments: 'Minnmouth seeks a potential vocabulary that exceeds conventional orthography, and which could, speculatively, evolve into a locally-aligned resource aligned with offshore technology' (Finlay et al. 2016, p. 5). In tracing the relationship between 'poetic devices and energy devices' (Finlay et al. 2016, p. 5) the collection suggests that much as renewable technologies draw their power from specific environments, so too does a poem's power relate to 'the sea of locality' within which 'language is energized by the gyring sound and sense I dialect is an energy resource' (Finlay et al. 2016, p. 44). In positioning poetry in relationship to technology, the collection as a whole presents a " tidal theory" of poetics' (Finlay 2016, p. 2) where dialect is understood as a form of 'energized language' that is able to disseminate the 'relationship between localism, culture, and energy solutions' (Finlay 2016, p. 2). Through his linguistic attentions to history and locality, for Finlay poetry becomes just one more

3 The collection's focus on devising a 'poetics for a drowned world' (Finlay et al. 2016, p. 5) is further expounded through the inclusion of an accompanying specially commissioned sound-piece by the artists Hannah Tuulikki and Lucy Duncombe, titled 'TideSong' which can be listened to here: https: / / tidesongs.bandcamp.com/releases. 
'device for transferring energy' (Finlay et al. 2016, p. 44), emerging as another technology through which to process, filter, transfer, capture, store and shap. meaning from the surrounding landscape.

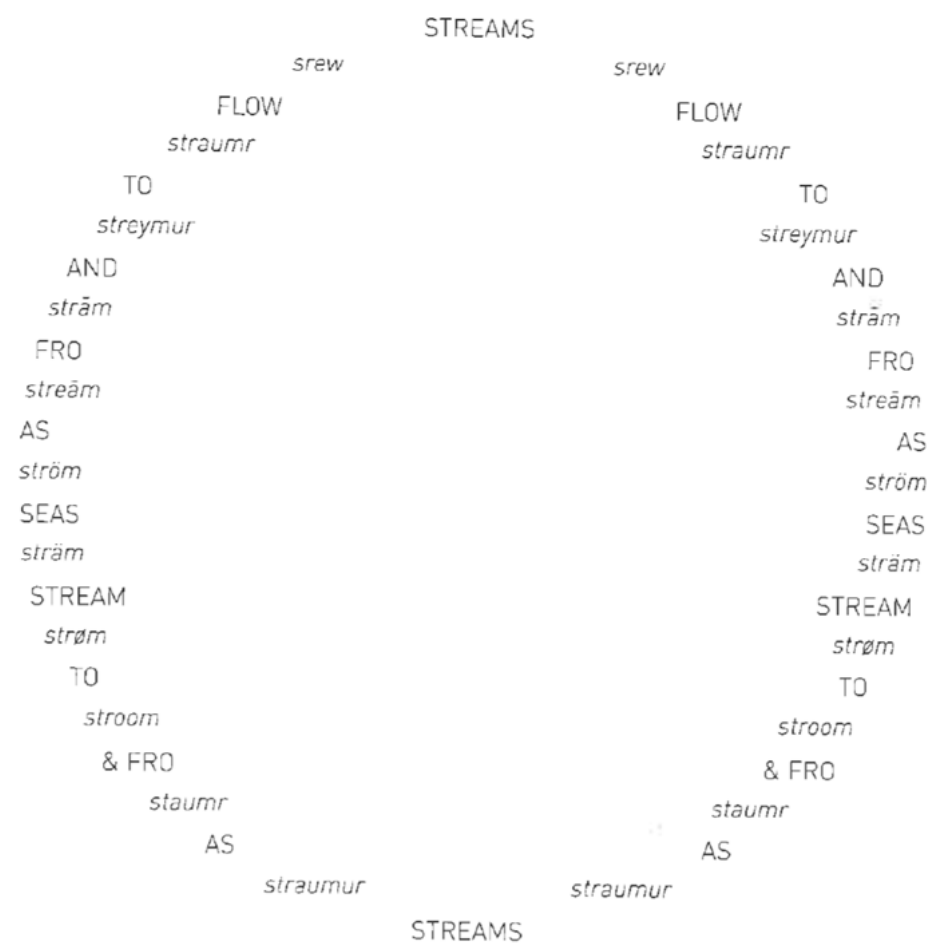

Figure 1. 'Streams', (Finlay et al. 2015, p. 48).

The collection serves to preserve the 'endangered expressions' (Finlay 2016, p. 1) of economically, culturally, and linguistically marginalized coastal communities, and in so doing actively explores the relationship between the extinction of language and environmental degradation. Across the collection the loss of language is tethered to the loss of the accompanying nonhuman environment where incumbent sea-level rise, ocean acidification, and extreme weather not only leads to the devastation of marine ecosystems, but evacuates these ecosystems of meaning and history. In the poem 'After Khlebnikov we used to say ... ', ', Finlay works to uncover the connections between the technical innovations of dialect and the 'preponderance of renewable l energy devices on Orkney' (Finlay et al. 2016, p. 44). In exposing the links between the production of energy and the preservation of language, the collection provocatively suggests that the survival of local languages rests on the creation of a 'post-carbon culture' (Finlay et al. 2016, p. 5). Throughout the collection, Finlay suggests that renewable energy technologies are not only aligned with environmentalist discourses but are also tethered to forms of social and cultural emancipation where the installation of low-carbon energy projects allows local communities to pursue forms of cultural and economic sovereignty. Much as the installation of renewable devices in Orkney's waters allows for communities to exist off-grid, so too does the 'expressivity of Norn' (Finlay et al. 2016, p. 44) allow the collection to disconnect from the 'universal language' of 'General English, British Petroleum, Standard Oil' (Finlay et al. 2016, p. 44). In suggesting that the 'standardization of language is a result of economies of scale' (Finlay et al. 2016, p. 44), the collection draws direct threads between petroleum production, linguistic hegemony, and environmental degradation. Declaring the need to put 'dialect before standard! windmills after petrolio!' (Finlay et al. 2016, italics in original, p. 44), the collection proposes that renewable technologies

4 The poem is inspired by the zaum poems of Velimir Khlebnikov, a poet of the Russian Futurist movement whose works sought to produce a form of transrational poetry that blends together 'neologisms, dialect, and ancient languages, lending it ears for sound over sense' (Finlay et al. 2016, p. 4). 
with their 'blades, tides, and phonemes' are able to 'blow away the smell of oil' (Finlay et al. 2016, p. 44) and thus ensure the production of a sustainable non-standardized future. Pointing towards a possible future that can exist 'after' the end of 'petrolio', the collection's creative investment in the 'sea of locality' signals towards the future survival of both land and language. But the reality of achieving this decentralized post-carbon future is not as simple as the poems in 'Minnmouth' would have us believe. As Watts notes elsewhere, while the Orkney archipelago is 'more than self-sufficient' (Watts 2016 , p. 7) and frequently produces $100 \%$ of its energy needs from wind, wave, and tide, Orkney's grid often runs at capacity. Despite its investment in innovative and emancipatory technologies, Orkney is still very much at the behest of mainland energy politics as due to the sheer amount of energy being produced by the islands:

The grid cannot cope. The operator, Scottish and Southern Energy (SSE), have taken emergency measures and in 2012 [issued] a moratorium on renewable energy generation. No more wind, wave or tide energy. The cable will melt and the entire electricity network will fuse.

(Watts 2016, p. 7)

Consequently, despite living next to incredibly energy-rich waters 'half the households [in Orkney] are in fuel poverty' (Watts 2016, p. 8). Thus, while a post-carbon future may have arrived in Orkney in the shap. of fantastical devices such as the OpenHydro turbine or the Oyster and Sea Snake wave energy convertors, the ailing fossil-fuel era energy infrastructure that underpins the islands and connects Orkney back to mainland Scotland currently prohibits this post-carbon future from becoming a lived reality for many of the archipelago's residents.

Responding to the question of energy sovereignty, the recent collaborative project 'Blàthan Briste I Broken Flowers' from the poet Lila Matsumoto and the sculptor Hannah Imlach further interrogates the links between oceanic technologies, creative practice, and energy autonomy. Across two residencies, one on the Isle of Eigg and another in the Monach Islands, Imlach and Matsumoto produced a series of works in response to the fluid interplay between natural ecosystems and island technologies that exist within the Hebridean environment. Through a series of site-specific artworks and poems 'Blàthan Briste I Broken Flowers' draws from the kinetic and cultural energy of the islands in order to interrogate 'the relationship between localism and technology' (Taigh Chearsabhagh Museum and Arts Centre 2017). Their respective works incorporate local responses to both ancient and modern technologies ranging from Neolithic quern stones (hand mills) and marine renewable technologies, to the military rocket ranges on Uist and St Kilda. Where the poetic works of Watts and Finlay look to the mythological and linguistic histories of the ocean as a means of mapping new relationship. with renewable technologies, the work of Imlach and Matsumoto is more concerned with comprehending renewable technologies through community histories and direct sensorial encounters with the marine environment.

Imlach's first energy-inspired piece 'Nautilus Turbine' is described as a 'sculptural response to the community-run energy infrastructure of the Isle of Eigg', and focuses on the island's hydroelectric scheme which has made 'the islander's self-sufficiency possible' (Imlach 2016). In opposition to the overloaded Orkney grid, the energy infrastructure of Eigg is not bound to the will of the mainland with Imlach highlighting the 1997 community buyout as a crucial factor in Eigg's ability to not only pursue, but live, a low-carbon future. The sculpture is inspired by the 'exertion and responsibility taken on by the people of Eigg in generating their own power and the autonomy, freedom and environmental understanding this has afforded them' (Imlach 2016). Taking the form of a 'personal turbine, activated by a swimmer' (Imlach 2016), the nautilus shell-inspired sculpture serves to filter the sensorial experience of Eigg's marine environments into scenarios of future sustainability. 'Nautilus Turbine' necessitates direct bodily engagement with marine environments, as in order to function the swimmer must immerse themselves within water and gently push the sculpture in order to activate its various kinetic components. As the editors of Thinking with Water suggest, 'whether we are upstream or downstream, distant or immersed [our] relation to any specific body of water affects our way of knowing its waters' (Chen et al. 2013, p. 4). The act of bodily immersion necessitated by 'Nautilus 
Turbine' illustrates the ethical potential of immersion, whereby the sustained interconnection between the human body and marine landscap. brings about new modes of ecological attention. As DeLoughrey suggests 'submersion brings about ethical transformations' (DeLoughrey 2017, p. 42). By exploring the relationship. between the potential energy of the body and the tidal energies found within bodies of water, the 'individual activation of the piece highlights questions of responsibility in relation to the generation of energy' (Imlach 2016). The immersive dynamics of the sculpture subsequently 'brings us back to ecopolitics and the need for more accountability to the waters we all share' (Chen et al. 2013, p. 12). Indeed, Eigg's decentralised renewable infrastructure only works because all of the islanders are 'aware of their allotted energy allowance and have been trained to monitor, maintain, and repair the system' (Imlach 2016). Thus while for Imlach renewable energy technologies align with a sense of sovereignty and sustainability, they also cultivate ethical concern for the watery environments that sustain the production of these emancipatory energies. Imlach's second renewable energy-inspired sculpture, titled 'Tide Quern', further explores localist approaches to island technologies. Akin to 'Nautilus Turbine' the piece is installed within the coastal landscap. where the sculpture's rotary blades are able to turn in tune with the tide. The piece engages with the fraught history of the use of quern stones in the Hebrides. The quern stone was a vital technology through which families were able to gain independence over food production as tenants were able to grind their own grain without paying for use of the land-owner's mill. The use of quern stones was subsequently forbidden and wealthy land-owners were given the power to break stones in order to ensure compliance with thirlage laws. Importantly, the sculpture's rotary shap. and function not only draws its inspiration from the early island technology of the hand mill, but from 'the imposing form of the OpenHydro turbines being tested at [EMEC]' (Imlach 2017), thus directly linking older histories of independent food production to new questions of energy autonomy in the islands. By turning water rather than grain, the piece serves to preemp. 'the arrival of these devices to other island communities' (Imlach 2017) and presents renewable technologies as a medium through which local communities can once again become self-sufficient.

Drawing on the relationship. between power, ecology, and technology, the first of Matsumoto's poetic responses to Imlach's work, titled 'Islet', works to consider the ways in which poetry itself can be understood as a form of technology. In 'Islet', poetic and sculptural craft are likened to one another, with Matsumoto aligning the sculptural processes and materials of Imlach's pieces to the formation of poetry:

Piece and buoy, all. This rock, gneiss, a-working at shells.

Sometimes more needed looking, missing a small element. Cross-section ease, like a twist. Incorporate spirals. Another's in the jig with the glue.

$[\ldots]$

Start from cardboard or cork, stone-crop or balsawood. Use straws, kidney-vetch, electrical tape, plastic or fabric, a scalpel often on a mat. Heartease.

(Matsumoto 2017a)

The poem's sensitivity towards different creative resources unveils multisensorial modes of knowing place; one informed by tools such as a 'scalpel', 'glue', and 'electrical tape', and another that is informed by maritime histories of navigation that include the 'moon', a 'large compass', and the tide, with a further dimension that encounters place through the specific island flora of 'kidney-vetch', 'wrack and marram' (Matsumoto 2017a). The poem brings these different modes of making and knowing into contact with one another through forms of 'play and association; but one that's moored to its specific shap. and materials' (Matsumoto 2017b).

As one of the first swimmers to activate 'Nautilus Turbine', Matsumoto's poetic responses work to further explore the ethical implications of immersion and suspension evident within Imlach's works. Matsumoto has remarked that her work is in part influenced by Val Plumwood's claim that 'creative writing can also play an important part by making visible new possibilities for radically open and 
non-reductive ways to experience the world' (Plumwood 2007, p. 17). For Matsumoto one of the key ways in which we can make these 'non-reductive' experiences 'visible', is to consider poetry as a 'sculptural tool' or an 'artefact of enchantment' (Matsumoto 2017a), that is able to activate new sensorial engagements with the surrounding environment. Espousing object-oriented poetics, 'Islet' is attentive to the range of tools and materials that construct our everyday environments. Throughout the poem, seemingly static objects accumulate new meanings where 'cork' is likened to 'moment' and the craft materials of 'electrical tape, plastic or fabric' create the conditions for 'Heartease'. By imbuing objects with such qualities, Matsumoto urges the need to adop. a renewed attention to the world in order to glean its full meaning. At one point the poem warns: 'Don't jump in the final steps' (Matsumoto 2017a). The line invokes images of plunging into water, but there is an underlying suggestion here that in order to sustain creative activity the artist must engage with the world slowly and steadily, taking care to notice and look. In its opening line, the poem emphasizes this need to immerse oneself in the surrounding environment, suggesting: 'sometimes more needed looking'. Advocating the need to 'Stay with the object and its worldly weight' (Matsumoto 2017a) Matsumoto's poetic responses build on Imlach's initial questions regarding relationship. between community, energy and environment, and serve to establish a new sense of kinship with the marine environment. In suggesting that the act of creation occurs through prolonged sensorial engagement with the external world, Matsumoto aligns poetry with conditions of immersion, where to be immersed is to plunge or sink oneself into a 'particular state of body or mind; to involve deeply, to steep. absorb, in some action or activity' (OED 2018). In opposition to the accelerated narratives of Greenvoe and The Cheviot, in 'Islet' the context of renewable energy technologies decelerates interactions with the marine environment. Rather than espousing a dynamics of immediacy and exhaustion, across the poem Matsumoto employs a sense of suspension and delay wherein a 'Journey in the open' becomes 'distilled to a maze' which suspends the progression of the poetic speaker. Moving from an initial 'a-working at shells' the poem becomes immersed in the task of creation, where through its meandering noticing of objects, the poem is able to finally locate that initial 'missing' 'small element' in its final lines: 'From that shellmade end, the boat's volcanic. Whereas up in the moon a little l element floated' (Matsumoto 2017a).

This sense of poetry as a tool of immersion and suspension builds on the school of new materialism in which critics such as Jane Bennett describe the emancipatory dynamics of enchantment as 'the suspension of chronological and bodily movement' that allows one to 'participate in a momentarily immobilizing encounter [and to experience a] "moment of pure presence"' (Bennett 2016, p. 5). Importantly this mode of suspension is not akin to inertia, but is instead understood as a form of 'acute sensory activity' that is both intimate and estranging, and correlates with a sense of 'having had one's nerves or circulation or concentration powers tuned up or recharged' (Bennett 2016, p. 5). In her second accompanying poem titled 'Plainsong', Matsumoto likens the poetic speaker to the 'Tide Quern' sculpture: 'In this way she moves shorebound waves and the hopeful minds I of the travellers' (Matsumoto 2017a). Tuned to the turn of the tide, the speaker is once again suspended in a moment of contemplation as 'no one knows where she came from, or what will take I place within her' (Matsumoto 2017a). The sense of contemplation soon gives way to forms of memorialization whereby the poem and sculpture become 'a monument to her: the ox and the plough and the seedjar, the harrow I and the sickle and the flail, the quern and the oven' (Matsumoto 2017a). In advocating the need to pay attention to the cultural, material, and creative resonances of everyday objects, Matsumoto's mode of poetic suspension and immersion enables her to access and notice the histories of inequality and oppression that permeate across the Hebridean islandscape. In positioning the violent histories of the quern stone alongside the new realities of wind and wave power, Matsumoto presents the marine environment as both an archive of historical trauma and the site of possible futures. Suspended between past and present, the poem tunes in to the surrounding marine energyscap. where 'Despite a canvas almost windless' (Matsumoto 2017a) the poem is 'recharged' (Bennett 2016, p. 5) by the power of the sea that 'thrums the dulsen reef' (Matsumoto 2017a). Here Matsumoto engages the ocean as a different sort of resource space to that present in earlier Scottish petronarratives. Likening 
the generation of renewable energy to the power of imagination, the poem works to extract a sense of inspiration from the movement of tide and wind where the power of the sea and the lapping of 'shorebound waves' fuels the craft of the poem that 'unfurls to tell the passage. Pleasure I and hardship. syllable and texture' (Matsumoto 2017a). Here Matsumoto's mode of poetic enchantment, prompts an understanding of poetry as a playful technology, as an immersive techne (a making or craft) that is able to join together history, ocean and energy. Across her works, Matsumoto's advocation for new modes of sensorial attention enables the poetic 'reorientation [of the ocean] from a world of stable surfaces to one of three-dimensional mobilities' (Steinberg and Peters, p. 259) and brings about the possibility for 'new understandings of mapping and representing; living and knowing; governing and resisting' (Steinberg and Peters, p. 261).

Across these visual and poetic projects, marine renewable technologies serve to activate new modes of cultural and ecological relation with the sea. By engaging with the physical dynamics and dimensions of offshore energy extraction, the respective work of Watts, Finlay, Imlach and Matsumoto present poetry as a material craft that is able to harness the creative, linguistic and historical energies of the ocean. In opposition to the earlier forms of extraction pursued during the boom time of North Sea oil, this new era of renewable technology brings about a markedly different temporal and cultural construction of marine space. Across these works the ocean is not relegated to the empty economic metaphors of liquidity, fluidity, 'green growth I blue bloom I venture capitalism' (Finlay et al. 2015, p. 14), but is instead engaged as a site of suspension, disruption and delay that directly contravenes and reveals historical systems of extraction and control. While dominant environmental narratives surrounding renewable energy production often position it as the 'green' and 'clean' solution to the polluted petro-ocean, the works present here do well to acknowledge the difficulties (both economic, social and environmental) evident in offshore marine energy production. Where the earlier Scottish texts respond to harmful petrocultural understandings of the ocean as a paradoxically empty space that harbours a seemingly inexhaustible stream of goods, in the renewable energy projects discussed here the sea is not understood as a smooth and blank aqua nullius, an empty space made ready for colonization by distant capital, but as a finite and turbulent material agency that engenders a distinct sense of risk and responsibility towards the blue. By engaging with the ocean as a visible, lived and material space, the work of contemporary Scottish artists and poets endeavours to present alternative modes of seeing and being with(in) marine space. Whether delving below the surface of the everyday, or immersing themselves within different energetic bodies of water, these projects invoke a 'productive state of suspension, between terrestrial human habitats and distant benthic and pelagic realms' (Alaimo 2012b, p. 490), and do so with the intention of recalibrating human relationship. with the ocean. In revealing, and revelling in, the technical experimentation that occurs within Scotland's waters, these collaborative projects promote an understanding of the ocean as a site of imaginative resistance upon which new, generative, low-carbon futures can be written.

Funding: This research received no external research funding.

Conflicts of Interest: The author declares no conflict of interest.

\section{References}

Alaimo, Stacy. 2012a. Dispersing Disaster: The Deepwater Horizon, Ocean Conservation, and the Immateriality of Aliens. In American Environments: Climate-Cultures-Catastrophe. Edited by Christof Mauch and Sylvia Mayer. Heidelberg: Universitätsverlag Winter, pp. 177-93.

Alaimo, Stacy. 2012b. States of Suspension: Trans-Corporeality at Sea. ISLE 19: 476-93. [CrossRef]

Bennett, Jane. 2016. The Enchantment of Modern Life: Attachments, Crossings, Ethics. Princeton: Princeton University Press. Boyer, Dominic, and Imre Szeman. 2017. Energy, Power, and Politics. In The Energy Humanities: An Anthology. Edited by Dominic Boyer and Imre Szeman. Baltimore: Johns Hopkins University Press, pp. 151-57.

Buell, Frederick. 2012. A Short History of Oil Culture: Or, the Marriage of Catastrophe and Exuberance. Journal of American Studies 46: 273-93. [CrossRef] 
Chen, Cecilia, Astrida Neimanis, and Janine MacLeod. 2013. Introduction. In Thinking with Water. Edited by Cecilia Chen, Astrida Neimanis and Janine MacLeod. Quebec: McGill-Queens University Press, pp. 3-23.

Dean, Arthur H. 1958. The Geneva Conference on the Law of the Sea: What was Accomplished. The American Journal of International Law 52: 607-28. [CrossRef]

DeLoughrey, Elizabeth. 2007. Roots and Routes: Navigating Caribbean and Pacific Island Literatures. Honolulu: University of Hawai'i Press.

DeLoughrey, Elizabeth. 2010. Heavy Waters: Waste and Atlantic Modernity. PMLA 125: 703-12. [CrossRef]

DeLoughrey, Elizabeth. 2017. Submarine Futures of the Anthropocene. Comparative Literature 69: 32-44. [CrossRef] Earle, Sylvia. 2009. The World Is Blue: How Our Fate and the Ocean's Are One. Washington, DC: National Geographic Society. Fergusson, Maggie. 2006. George Mackay Brown: The Life. London: John Murray.

Finlay, Alec. 2016. Minnmouth Project Summary. Creative Carbon Scotland. Available online: https://www. creativecarbonscotland.com/wp-content/uploads/2017/01/MinnMouth-project-summary.pdf (accessed on 7 November 2018).

Finlay, Alec, Laura Watts, and Alastair Peebles. 2015. Ebban an Flowan. Dunbar: Morning Star.

Finlay, Alec, Hanna Tuulikki, and Lucy Duncombe. 2016. Minnmouth. Dunbar: Morning Star.

Freeman, Harrop A. 1970. Law of the Continental Shelf and Ocean Resources-An Overview. Conrnell International Law Journal 3: 105-20.

Gladwin, Derek. 2017. Ecological Exile: Spatial Injustice and Environmental Humanities. Oxon: Routledge.

Haraway, Donna. 1988. The Science Question in Feminism and the Privilege of Partial Perspective. Feminist Studies 14: 575-99. [CrossRef]

Imlach, Hannah. 2016. 'Nautilus Turbine'. Hannahimlach.com. Webpage. Available online: https://www. hannahimlach.com/Nautilus-Turbine (accessed on 7 November 2018).

Imlach, Hannah. 2017. 'Tide-Quern'. Hannahimlach.com. Webpage. Available online: https:/ /www.hannahimlach. com/Tide-Quern (accessed on 7 November 2018).

Jones, Michael. 2012. Udal law and Contested Histories of Land Tenure and Landscap. in Orkney and Shetland. Latvijas Zinatnu Akademijas Vetis. A Dala. Humanitaras Zinatnes 66: 105-18.

Larminie, F. G., R. B. Clark, J. K. Rudd, M. L. Tasker, John Ivan George Cadogan, R. B. Clark, and J. P. Hartley. 1987. The History and Future of North Sea Oil and Gas: An Environmental Perspective. Philosophical Transactions of the Royal Society of London, Series B. Biological Sciences 316: 487-93. [CrossRef]

Logar, Ernst. 2011. Invisible Oil. New York: Springer.

Macdonald, Graeme. 2015. Commentary. In The Cheviot, the Stag, and the Black, Black Oil. Edited by Graeme Macdonald. London: Bloomsbury, pp. 17-68.

Macdonald, Graeme. 2017. "Monstrous Transformer": Petrofiction and World Liteature. Journal of Postcolonial Writing 53: 289-302. [CrossRef]

Mackay Brown, George. 1972. Greenvoe. London: Hogarth.

MacLeod, Janine. 2017. Holding Water in Times of Hydrophobia. In Petrocultures: Oil, Politics, Culture. Edited by Sheena Wilson, Adam Carlson and Imre Szeman. Quebec: McGill-Queens University Press, pp. $264-87$.

Matsumoto, Lila. 2017a. Poetic Technologies: Exploring Hebridean Renewable Energy Production through Poetry. Paper presented at Bath Sp. University's Intercultural Communication through Practice Research Group. Bath Sp. University, Bath, UK, November 15.

Matsumoto, Lila. 2017b. Dune Cradle: Encounter and Enchantment. Available online: http:/ /www.hannahimlach. com/Dune-Cradle (accessed on 9 November 2018).

McDorman, T. 2015. The Continental Shelf. In The Oxford Handbook of the Law of the Sea. Edited by Donald Rothwell, Alex Oude Elferink, Karen Scott and Tim Stephens. Oxford: Oxford University Press, pp. 182-201.

McGrath, John. 2015. The Cheviot, the Stag, and the Black, Black Oil. Edited by Graeme Macdonald. London: Bloomsbury, pp. 84-164.

Mentz, Steve. 2015. Shipwreck Modernity: Ecologies of Globalization, 1550-1719. Minneapolis: University of Minnesota Press.

OED. 2018. Immersion. Oxford: Oxford University Press, Available online: http:/ / www.oed.com/view/Entry/ 91885? redirectedFrom=immersion (accessed on 17 January 2019).

Price, Rachel. 2017. Afterword: The Last Universal Commons. Comparative Literature 69: 4-53. [CrossRef]

Plumwood, Val. 2007. Journey to the Heart of Stone. In Culture, Creativity and Environment: New Environmentalist Criticism. Edited by Fiona Becket and Terry Gifford. Amsterdam: Rodopi, pp. 17-35.

Rozwadowski, Helen. 2010. Oceans Depths. Environmental History 15: 520-25. [CrossRef] 
Steinberg, Philip, and Kimberley Peters. Wet Ontologies, Fluid Spaces: Giving Depth to Volume through Oceanic Thinking. Environment and Planning D: Society and Space 33: 247-64. [CrossRef]

Taigh Chearsabhagh Museum and Arts Centre. 2017. Blàthan BristeBroken Flowers. Available online: https: / / www.taigh-chearsabhagh.org/events/blathan-briste-broken-flowers / (accessed on 6 September 2018).

The Offshore Valuation Group. 2010. The Offshore Valuation: A Valuation of the UK's Offshore Renewable Energy Resource. Available online: http://publicinterest.org.uk/offshore/downloads/offshore_valuation_exec.pdf (accessed on 10 September 2018).

Treves, Tulio. 2015. Historical Development of the Law of the Sea. In The Oxford Handbook of the Law of the Sea. Rothwell, Donald, Alex Oude Elferink, Karen Scott, and Tim Stephens, eds. Oxford: Oxford University Press, pp. 1-24.

UK Continental Shelf Act. 1964. Continental Shelf Act. The American Journal of International Law 58: 1085-90.

Watts, Laura. 2014. Liminal Futures: Poems for Islands at the Edge. In Subversion, Conversion, Development: Cross-Cultural Knowledge Exchange and the Politics of Design. Edited by James Leach and Lee Wilson. Cambridge: MIT Press, pp. 19-39.

Watts, Laura. 2016. The Electric Nemesis: Making Energy Futures without Hubris. Paper presented at Electrifying Anthropology, Durham University, March 18; Available online: http:/ / sand14.com/archive/papers/WattsElectricNemesis-final.pdf (accessed on 7 November 2018).

Watts, Laura, and Brit Ross Winthereik. 2018. Ocean Energy at the Edge. In Ocean Energy: Governance Challenges for Wave and Tidal Stream Technologies. Edited by Glen Wright, Sandy Kerr and Kate Johnson. London: Routledge.

Watts, Laura. 2018. Beside the Ocean of Energy Future Time. Paper presented at Petrocultures 2018: Transitions, University of Glasgow, Glasgow, Scotland, August 29.

Yaeger, Patricia. 2010. Sea Trash, Dark Pools and the Tragedy of the Commons. PMLA 125: 523-45. [CrossRef]

(C) 2019 by the author. Licensee MDPI, Basel, Switzerland. This article is an open access article distributed under the terms and conditions of the Creative Commons Attribution (CC BY) license (http://creativecommons.org/licenses/by/4.0/). 